\title{
Effects of Paddy Husk Biochar on Selected Physical and Chemical Properties of the Low Humic Gley Soil in the Low Country Wet Zone
}

\author{
Najim M.M.M. ${ }^{1}$ and Moragoda N. $^{2 *}$ \\ ${ }^{1}$ South Eastern University of Sri Lanka \\ ${ }^{2}$ University of Kelaniya, Sri Lanka \\ *nishani.moragodal@gmail.com
}

\begin{abstract}
Biochar made by pyrolysis of various types of biomass has been recognized in recent years as a potential soil amendment. Studies from different parts of the world using a variety of feedstock materials, process conditions and applications in different soil types have reported a diverse range of effects that are sometimes conflicting. Though paddy husk biochar (Kara dahayya) has been used in Sri Lankan paddy fields since ancient times, the actual outcome of this is uncertain owing to the limited number of research that have been carried out. This study focused on studying the effects of paddy husk biochar made by traditional methods, with and without other soil amendments such as compost, mineral fertilizers and their combinations on selected physical and chemical properties of Low Humic Gley soil used for paddy cultivation in the Low Country Wet Zone.
\end{abstract}

A pot experiment was carried out from May to August 2015 with six treatments, namely; T1Soil only (Control), T2-Soil+Paddy husk biochar, T3-Soil+Compost, T4-Soil+NPK(mineral fertilizer), T5- Soil+Compost+Paddy husk biochar and T6-Soil+NPK+Paddy husk biochar with four replicates for each treatment. The physical properties of soil were analyzed initially as well as at the end of the experiment, while soil chemical properties were analyzed once every 3 weeks during the study period.

The results revealed that paddy husk biochar used in this experiment serve as both a soil fertilizer and as a soil conditioner in the test soil. Principal Component Analysis (PCA) revealed that the application of paddy husk biochar along with mineral fertilizer (T6) is the most effective treatment for this soil. This treatment recorded the highest porosity of $60.26 \%$ and the second lowest bulk density of $1.10 \mathrm{~g} / \mathrm{cm}^{3}$. Also increasing trends in soil $\mathrm{pH}$, organic carbon, total nitrogen and cation exchange capacity were observed in this treatment. Based on these results, it can be concluded that the application of paddy husk biochar along with recommended levels of mineral fertilizer is effective in improving certain properties of Low Humic Gley soil of the Low Country Wet Zone.

Keywords: Paddy husk biochar, Low humic gley soil, Paddy cultivation, Soil physical and chemical properties, Soil amendments

Proceedings of the International Forestry and Environment Symposium 2016, Department of Forestry and Environmental Science, University of Sri Jayewardenepura, Sri Lanka. 